\title{
Factors Associated with Secondary Traumatic Stress among Emergency Nurses: An Integrative Review
}

\author{
Hamza F. Ratrout ${ }^{1}$, Ayman M. Hamdan-Mansour ${ }^{2}$ \\ ${ }^{1}$ Post Graduate Study, School of Nursing, The University of Jordan, Amman, Jordan \\ ${ }^{2}$ Department of Community Health Nursing, School of Nursing, The University of Jordan, Amman, Jordan \\ Email:hmzehr@yahoo.com, aymanjabay@gmail.com
}

How to cite this paper: Ratrout, H.F. and Hamdan-Mansour A.M. (2017) Factors Associated with Secondary Traumatic Stress among Emergency Nurses: An Integrative Review. Open Journal of Nursing, 7, 1209-1226.

https://doi.org/10.4236/ojn.2017.711088

Received: October 5, 2017

Accepted: November 7, 2017

Published: November 10, 2017

Copyright $\odot 2017$ by authors and Scientific Research Publishing Inc. This work is licensed under the Creative Commons Attribution International License (CC BY 4.0).

http://creativecommons.org/licenses/by/4.0/

(c) (i) Open Access

\begin{abstract}
Background: Emergency nurses are exposed to traumatized patients as part of their job. Secondary exposure to trauma may lead to traumatic stress similar to those experienced by the primary victim. Emergency nurses develop secondary traumatic stress symptoms more than other nurses due to nature of emergency departments. The consequences of secondary traumatic stress can be noticed at personal, interpersonal, or organizational level. Objectives: This integrative review aimed to explore the literature on the factors attenuate or enhance occurrence of secondary traumatic stress among emergency nurses, to identify these factors, and to provide recommendations for research in the field. Method: An integrative literature review of quantitative and qualitative studies on secondary traumatic stress in emergency nurses were published in English language between 2000 and 2017 through the following data bases: Cumulative Index to Nursing and Allied Health Literature (CINAHL), ProQuest, Medline, PubMed, Google Scholar, SAGE Journals, Wiley on Line Library, Science Direct and EBSCOhost Sources. Results: The review identified that factors associated with secondary traumatic stress can be classified into personal and organizational factors. Findings on personal factors such as age, gender, and experience are controversial, whereas organizational factors such as trauma case load and perceived organizational support were found to predict traumatic stress more than the personal factors. Conclusions: Emergency nurses are at risk to develop traumatic stress and need to be aware to the contributing factors in order to maintain their well being. Further research is required to explore the factors enhance or attenuate occurrence of secondary traumatic stress.
\end{abstract}

\section{Keywords}

Secondary Traumatic Stress, Emergency, Nurses, Factors, Integrative Review 


\section{Introduction}

Emergency department (ED) is generally viewed as an emotionally charged area. The ED, eventually, is described as physically and psychologically overwhelming area for both health professionals and nurses. However, the ED nurses are the key personnel, and act as the front line in dealing wounded and hemorrhaging victims, caring of traumatized victims, and seeing dying patients on daily basis [1]. This makes ED nurses subject to various forms of burden and psychological disturbances such as stress, dissatisfaction, and burnout [2]. The ED nurses suffer psychological disturbances due to caring of traumatized patients reaching unpleasant outcomes such as deaths and losses proposing a connection between caring of traumatized patients and psychological disturbances among ED nurses [3]. An increased concern about trauma is noted in the last decades due to increased rates of traumatic events caused by natural and man-made disasters [4]. Therefore, the Diagnostic and Statistical Manual of Mental Disorders, 5th Edition (DSM-5) has extended the conceptualization of trauma to include indirect exposure to trauma through hearing, witnessing, and learning about traumatic events. This infers that the concept of trauma is no more limited to direct experience of threatening assault, but also includes secondary exposure to traumatic events [5]. The reconceptualization of trauma has called for reconsidering the experiences of ED nurses whose main responsibility is to provide care to psychologically and physically traumatized patients. Thus, the term "traumatic stress" is emerging and been introduced in nursing literature to understand the nature of experience for nurses providing care for traumatized patients. Traumatic stress is a term used to describe the negative impacts experienced by healthcare professionals caring of traumatized patients [6]. Trauma and its related effects may be transferred secondarily to health professionals interacting with victims. Thus, stress encountered due to indirect exposure to trauma is called Secondary Traumatic Stress (STS). This type of stress has been recognized by McGibbon, et al. as one of the major types of stress encountered by nurses [7]. An increasing concern is noted about the indirect effect of trauma on ED nurses due to its serious consequences on their psychosocial wellbeing and their quality performance [8]. The literature has marked numerous factors that may enhance or attenuate occurrence of STS among helping professionals, however; little is known about factors associated with STS among ED nurses. It is imperative for both the quality care managers to ameliorate factors lead to development of STS among ED nurses [9].

The overall purpose of this integrative review is to explore the theoretical and empirical literature discussing the factors associated with development of STS among health professionals, in general, and among ED nurses, in particular. The specific aims are: to summarize and identify these factors, to provide evidence-based recommendations for future research and instrument development in the field, and to inform the priorities for future research evidence in this area. Understanding these factors may help ED nurses maintaining their ability to 
experience work fulfillment and contribute to patient quality of care.

\section{Methodology}

Literature search followed Whittemore and Knafl's framework of integrative review process [10]. This framework was consulted as it facilitates inclusion of a large number of variables and addresses both qualitative and quantitative studies to provide a broad perspective on the topic of interest. A comprehensive and systematic search process was conducted to retrieve the factors identified in both the qualitative and quantitative. The inclusion criteria were set to include only the followings: resources that are relevant to the review purpose and topic from different designs and methods with no geographical limits, resources published in peer reviewed journals in English language from 2000 to June 2017, resources that are relevant to nurses population and other professionals comparable to nurses such as psychology, trauma workers, and social works, and primary theoretical and empirical resources. The articles which were excluded from search process those that focused on populations not comparable to nurses, articles published in languages other than English, articles published older than year of 2000, unpublished articles, and articles not relevant to the review purpose. Search process was completed on 8th April 2017 and updated on 8th June 2017. Search was conducted using the following online bibliographic data bases: Cumulative Index to Nursing and Allied Health Literature (CINAHL), ProQuest, Medline, PubMed, Google Scholar, SAGE Journals, Wiley on Line Library, Science Direct, and EBSCOhost. These databases were consulted to include nursing, psychology, medical, and multidisciplinary areas. Database searches were conducted using following terms: secondary traumatic stress, secondary trauma, secondary exposure, secondary stress, indirect trauma, post-traumatic stress disorder, and secondary post-traumatic stress alongside the terms: trauma, nurses, emergency and factors. Boolean operators (AND, OR) have been applied separately and in combination with the keywords to expand, combine, or exclude keywords in a search to narrow down the results and reach a more focused and productive results. Search process has also targeted resources other than online data bases such as: websites of relevant research institutes and other older resources such as published books and theoretical literature about the topic. Manual search of the reference lists from selected citations was conducted to locate relevant and significant resources that were not identified in the online databases. Critical Appraisal of the relevant articles was conducted based on the guidelines suggested by Critical Appraisal Skills Program (CASP). Accordingly, each study was appraised against the following questions: was the study valid? What were the results? And are the results useful? All searched articles were evaluated in terms of their weaknesses and strengths to minimize the validity threats [11]. The procedure used to locate the literature included in this review is illustrated in Figure 1. Whittemore and Knafl's framework was applied to extract data from the primary articles. Significant data were 


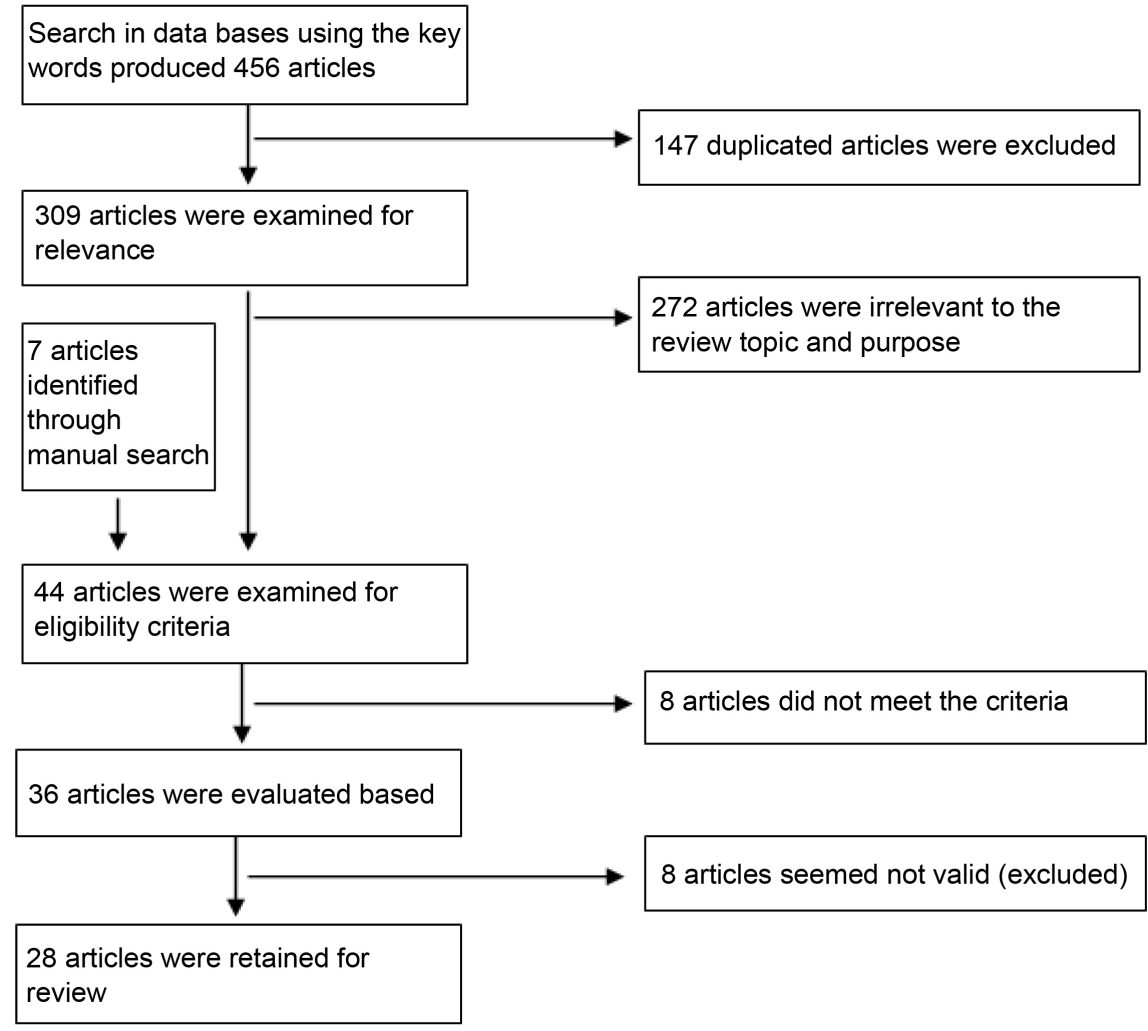

Figure 1. Flow diagram shows the procedure used to locate the literature.

extracted in light of the well-specified review purpose and predetermined set of STS factors. This facilitated the process of data extraction particularly differentiation between relevant and irrelevant articles, given that the previous studies on STS factors examined wide range of factors [10]. A data matrix was developed to display the extracted data from each article. The facilitated extraction of data from articles subscribed to various methodologies. Constant comparison procedure was also used to extract the data from the qualitative studies to ensure distinction of emerged themes and relationships. Extracted themes were compared to each other so that similar themes were grouped together to reduce the extracted data.

\section{Results}

\subsection{Theoretical Perspectives}

Trauma Transmission Model is one of the early models attempted to explain the process by which the trauma effect is transmitted from victim to helper. This model asserts that empathy is the core concept in development of compassion stress. It assumes that trauma workers who share empathy with traumatized victims may experience compassion stress. The prolonged compassion stress may result in STS [12]. The Ecological Framework of Trauma Dutton and Rubinstein model also aimed to explain the process in which the STS developed among trauma workers. The main assumption underlies this model is that STS results 
from exposure to traumatic material in a linear process, and the variability in the levels of STS is moderated by a group of personal and environmental variables that poster or attenuate occurrence of STS symptoms. These factors act as mediators for the occurrence of STS among trauma workers [13]. Another model is the Nurse as Wounded Healer theory. This theory addressed the secondary exposure to trauma among nursing population, and acknowledges that nurses working in stressful environment such as emergency care unit may experience personal trauma, professional trauma, or both. This theory assumes that nurse who exposed to trauma will either become walking wounded and remain restricted to traumatic experience, or become a wounded healers who transcendence the trauma experiences. The concept of walking wounded describes the impact of working in traumatic environment such as emergency care area [14]. Accordingly, the ED nurses are viewed as wounded healers who require transcending the traumatic experiences successfully to be able to provide optimum. These models are commonly having little empirical research evidence to suggest that they are either effective or appropriate to explain this process. Also, each of these models explained one or more aspects of the construct of secondary exposure to others' trauma, but each one of them failed alone to capture the whole aspects of this construct.

\subsection{Prevalence of STS in ED Nurses}

Previous studies from different geographic areas showed that prevalence of STS among ED nurses is variable and high. Adriaenssens et al. evaluated the prevalence of STS among 248 nurses working in emergency units from 15 Belgian general hospitals and found that $8.5 \%$ of the participants reached the clinical level of post traumatic stress [15]. Another study by Duffy et al. evaluated the prevalence of STS among 105 Irish nurses in three different emergency units using the STS scale. Findings showed that $64 \%$ of the samples have met the criteria for STS [1]. In a very recent study in Scotland, Morrison and Joy found that 75\% of a sample of emergency nurses reported at least one symptom of STS during the time of the study, and $39 \%$ of them met the whole criteria of STS [16]. These rates are alarming and require attention of stakeholders. Differences in characteristics of health care systems across countries and regions in which these studies have been conducted may explain the variation in the reported rates of STS. Also the methods and measurement issues vary as the criteria of STS have been changed after the year 2013 with release of DSM-5 [5]. For example, some researchers reported the incidence rate of STS symptoms in term of occurrence of the three symptoms of STS (intrusion, avoidance, and hyper-arousal), while, other researchers reported occurrence of any of these symptoms. However, it is recommended that researchers need to follow Bride's guidelines to report the incidence and prevalence of STS [17]. Moreover, variation in rates is also attributed to methods of measurement of STS. Although the Secondary Traumatic Stress Scale (STSS) was reported as the only scale that exclusively measures STS 
[18] [19], various studies used scales that were constructed to measure STS such as scales measuring compassion fatigue and burn out.

\subsection{Risk Development}

Emergency unit is a stressful, fast-paced, and demanding environment [16]. The ED nurses are routinely caring of traumatized patients and life threatening. Such daily scenarios place nurses at an increased risk for occurrence of STS symptoms [2]. Psychological responses to traumatic events often seen as normal, and usually diminishes within short period of time. However, repetitive exposure to traumatic events may hinder the normal recovery process and may result in the development of psychological disorders [20]. Consequently, the ED nurses are at risk and tend to develop STS more than others due to nature being repetitively exposed to traumatized individuals [21]. Another factor may contribute to STS among the ED nurses is being involved in a high level empathetic relationship with the traumatized individuals [22]. Sharing empathy is a central concept and key component in the process of developing STS among nurses [21]. Although empathy is a core therapeutic technique in nursing care, however, empathy may transfer trauma feelings from victims to nurses. Consequently, nurses either have positive feelings about their ability to help others which is known as compassion satisfaction, or have negative feelings that may precipitate for STS [3]. Furthermore, imminence, nature, and increased frequency of traumatic events confronted by nurses in ED departments have also contributed to development of STS among ED nurses. The repetitive exposure to such events is assumed to be associated with serious psychological and physical consequences on nurses in ED departments and can contribute to high risk of STS among them [15].

\subsection{Consequences of STS on ED Nurses}

Engaging in caring relationship with traumatized victims represented a source of stress that has an impact on the physical and mental integrity of the trauma workers [23]. Secondary exposure to trauma affects the ED nurses physically and mentally [24]. Studies showed that nurses in ED reported high levels of traumatic stress, anxiety, depression, and somatic complaints [15]. The consequences of untreated STS among ED nurses found to influence nurses' capacity, quality of care provided, and organizational outcomes [3]. Each of the STS symptoms can be linked to group of negative consequences that can be noticed at personal, interpersonal, or organizational level [25]. At personal level, STS can disrupt normal life and leads to difficulty in enjoying life [25]. Intrusive thoughts may produce tactile sensations, thought distortion, flashbacks, and nightmares [2]. Moreover, reckless and risk-related behaviors were observed among ED nurses. For example, Donnelly and Siebert reported that $40 \%$ of the emergency care personnel, including nurses, use drugs and alcohol to cope with traumatic stress [26]. Moreover, Duffy et al. found that ED nurses who reported high levels of STS symptoms use alcohol as coping strategy to manage the STS symptoms [1]. 
Similarly, Von Rueden and colleagues found that trauma nurses who demonstrated high level of STS symptoms were more likely to use medicines to cope with stress [8]. Ramifications of STS may extend the nurse' personal life to affect his/her interpersonal relationships. Hyper-arousal symptoms have been manifested in ED nurses as startle response in providing care and anticipating bad events. This could lead to interpersonal conflicts with patients and other health care professionals [2]. Rainville maintained that hyper-arousal symptoms cause nurses to perceive colleagues and patients as threat leading to violent and nonprofessional relationships [26].

At the organizational level, the STS symptoms may influence nurses' performance and the care they provide [15]. Mealer and Jones concluded that STS negatively impact the quality of life among nurses and their patients causing dissatisfaction and poor health care outcomes [2]. Moreover, the analysis of literature showed that STS is linked to job dissatisfaction, retention, burnout and tendency to leave nursing. Bride and Kintzle (2011) investigated the relationship between job satisfaction and STS among substance abuse counselors. Findings indicated that lower level of job satisfaction was associated with higher level of STS [27]. This finding was supported by Cieslak and colleagues who found similar findings in their analysis of the relationship between job burnout and STS among trauma workers [28]. Another issue is the consequences of avoidance. Rainville reported higher levels of arriving late, absenteeism, leaving workplace early, and episodes of sick leave among nurses experience high level of STS symptoms [25]. Avoidance among nurses has been observed in terms of avoiding taking care of patients who remind them with previous traumatic situations [2] [29]. In addition, Duffy et al. have also found that ED nurses who reported high levels of STS symptoms have higher tendency to change their career in comparison with nurses who did not report high level of STS symptoms [1]. These ramifications might lead to deterioration in the quality of patient care and patient health status [29]. With high prevalence of STS among ED nurses and its devastating effects, the STS become an area of concern that needs attention and further investigation. Despite the salience of STS consequences, less research has been directed to investigate the impact of secondary exposure to trauma on ED nurses in comparison with those studies examined the prevalence of STS and its predicting factors. One of the possible explanations is lack of conceptualization for the relationship between STS and these proposed consequences. Moreover, the models explain the STS ignored addressing effects of secondary exposure on nurses, and rather, focused prevalence and contributing factors.

\subsection{Factors Associated with STS}

The existing literature identified several factors that may enhance or attenuate occurrence of STS among ED nurses. Theoretically, these factors have been conceptualized to moderate the relationship between secondary exposure to traumatic events and the subsequent symptoms of STS on the care provider. These 
factors have to be considered to understand the process of developing STS symptoms [30].Altogether, nine factors were identified as risk or preventive factors for STS and pooled into two main categories: personal factors and organizational or work-related factors. The personal factors identified in the literature are: age [22], gender, years in nursing profession, professional seniority [31], educational level [32], history of sexual assault [30], trauma training, social support, personal trauma history [22], and spirituality level [2]. While the organizational factors identified in the literature are: trauma case load [22], organizational support [33], clinical supervision, and relationship with colleagues [30]. The following sections will explore and discuss the literature found on a selected group of these factors in details and combine findings from both the quantitative and qualitative literature. The key findings of reviewed studies are summarized in Table 1.

\subsubsection{Personal Factors}

Several studies examined the relationship between nurses' ages and STS and presented controversial reports. Being young has number of inclusion on the psychological adaptation to stressful events. Studies showed that younger people are at higher risk to mal-adaptation than older people, and thus, at higher risk to develop STS than younger ones. However, nurses are professional health care personnel who have received training and education to manage health care problems. It is expected that nurses in ED who are trained to manage traumatized people are prepared to all bio-psychosocial consequences. Being diagnosed or experiencing STS infers that secondary trauma did influence nurses in spite of their training and experience in nursing. Nevertheless, studies showed paradoxical findings in which age (age progression) has no clear connection to development of STS among emergency nurse.

An earlier study by Dominguez-Gomez and Rutledge reported that older nurses in ED demonstrated higher level of STS symptoms [31]. While Dworkin et al. investigated the role of age in predicting STS among a sample of 164 staff work with survivors of sexual assault in rape crisis centers and found that younger staff had higher levels of STS symptoms in comparison to older staff [30]. However, other studies found no connection between age and STS. For example, Măirean et al. investigated the relationship between STS and age among a sample of 52 healthcare providers including ED nurses in Romania and found no correlations between age and STS [34]. Furthermore, a meta-analysis by Hensel et al. reported significant but weak association between STS and age [22]. Variation among these findings implies that association between age and developing STS requires further exploration as long as the empirical literature is contradicting. To summarize, the literature has, actually, presented inconsistent reports regarding age-STS connection. This could be related to lack of appropriate methodology to measure the effect of age such as using cohorts, time series, or controlling age statistically. Moreover, age of nurses in ED is almost different (less) than nurses in other departments, and turnover is another concerning issue. 
Table 1. Details of the key studies included in the review.

\begin{tabular}{|c|c|c|c|c|}
\hline Author & Year & Design & Population & Key findings \\
\hline $\begin{array}{l}\text { Adriaenssens and } \\
\text { colleagues }\end{array}$ & 2012 & $\begin{array}{l}\text { cross-sectional } \\
\text { survey }\end{array}$ & $\begin{array}{l}\text { Emergency } \\
\text { nurses } \\
(\mathrm{N}=248)\end{array}$ & $\begin{array}{l}\text { - } \text { Social support had a protective effect against STS } \\
\text { - Organizational support had a protective effect against STS } \\
\text { - Personal factors were not associated with STS } \\
\text { - Level of trauma exposure was associated with STS } \\
\text { - Coping is a predictor of STS }\end{array}$ \\
\hline Choi & 2010 & $\begin{array}{l}\text { cross-sectional } \\
\text { survey }\end{array}$ & $\begin{array}{l}\text { Social } \\
\text { workers } \\
(\mathrm{N}=154)\end{array}$ & $\begin{array}{l}\text { - Social workers exhibited mild levels of STS } \\
\text { - } 65 \% \text { of the social workers had at least one or more STS symptoms } \\
\text { - Organizational factors are not related to developing of STS } \\
\text { - Past trauma history is positively related to STS } \\
\text { - Social support was marginally significant predictor of STS }\end{array}$ \\
\hline $\begin{array}{l}\text { Dominguez-Gomez } \\
\text { and Rutledge }\end{array}$ & 2009 & $\begin{array}{l}\text { Cross sectional } \\
\text { study }\end{array}$ & $\begin{array}{l}\text { Emergency } \\
\text { nurses } \\
(\mathrm{N}=67)\end{array}$ & $\begin{array}{l}\text { - } 33 \% \text { of the sample met all criteria for a diagnosis of STS } \\
\text { - } 85 \% \text { of the sample reported at least one symptom of STS } \\
\text { - } \text { Age was found positively related to STS } \\
\text { - No association between years of experience and STS } \\
\text { - No association between level of trauma exposure and STS }\end{array}$ \\
\hline $\begin{array}{c}\text { Duffy and } \\
\text { Colleagues } 2015\end{array}$ & 2015 & $\begin{array}{l}\text { cross-sectional } \\
\text { study }\end{array}$ & $\begin{array}{l}\text { Emergency } \\
\text { nurses } \\
(\mathrm{N}=105)\end{array}$ & $\begin{array}{l}\text { - } 64 \% \text { of the sample met the met the diagnostic criteria for STS } \\
\text { - Irish emergency nurses experienced high level of STS symptoms } \\
\text { - Lack of organizational support was linked to work-related traumatic } \\
\text { stress } \\
\text { - High level of STS was linked to intention to change the career }\end{array}$ \\
\hline $\begin{array}{c}\text { Dworkin and } \\
\text { colleagues }\end{array}$ & 2016 & $\begin{array}{l}\text { cross-sectional } \\
\text { study }\end{array}$ & $\begin{array}{l}\text { Rape crisis } \\
\text { workers } \\
(\mathrm{N}=164)\end{array}$ & $\begin{array}{l}\text { - } \text { personal and organizational factors related to STS } \\
\text { - } \text { Age was inversely related to STS } \\
\text { - Supervision was inversely related to STS } \\
\text { - Higher trauma loads accounted for high levels of STS } \\
\text { - Some, but not all, individual-level variables are associated with STS }\end{array}$ \\
\hline $\begin{array}{l}\text { Townsend and } \\
\text { Campbell }\end{array}$ & 2009 & $\begin{array}{l}\text { Qualitative in- } \\
\text { terviews }\end{array}$ & $\begin{array}{l}\text { Sexual assault } \\
\text { nurses } \\
(\mathrm{N}=144)\end{array}$ & $\begin{array}{l}\text { - } \text { Organizational factors played a role in developing STS } \\
\text { - Higher trauma case load was associated with more STS symptoms } \\
\text { - } \text { More continuous training was associated with more STS symptoms } \\
\text { - Higher peer support was associated with less STS symptoms } \\
\text { - Higher organizational support was associated with more STS symptoms } \\
\text { - Higher educational level was associated with less STS symptoms }\end{array}$ \\
\hline $\begin{array}{l}\text { Mairean and } \\
\text { colleagues }\end{array}$ & 2014 & Cross sectional & $\begin{array}{l}\text { Emergency } \\
\text { practitioners } \\
(\mathrm{N}=52)\end{array}$ & $\begin{array}{l}\text { - No significant correlations between age and STS symptoms } \\
\text { - No significant correlations between experience and STS } \\
\text { - Repeated exposures to traumatic material may to lead to STS }\end{array}$ \\
\hline Morrison and Joy & 2016 & $\begin{array}{l}\text { mixed method } \\
\text { design }\end{array}$ & $\begin{array}{l}\text { Emergency } \\
\text { nurses } \\
(\mathrm{N}=50)\end{array}$ & $\begin{array}{l}\text { - } 75 \% \text { of the sampled reported at least one STS symptom } \\
\text { - } 39 \% \text { of the sample met the criteria for diagnosis of STS } \\
\text { - } \quad \text { Occupational stressors influenced the experiences of STS } \\
\text { - } \quad \text { Social support was cited as beneficial tools for managing STS }\end{array}$ \\
\hline $\begin{array}{l}\text { Von Rueden and } \\
\text { colleagues }\end{array}$ & 2010 & & $\begin{array}{l}\text { Trauma nurses } \\
\qquad(\mathrm{N}=262)\end{array}$ & $\begin{array}{l}\text { - Negative association between STS symptoms and years of experience } \\
\text { - Trauma nurses who demonstrated high level of STS symptoms were } \\
\text { more likely to use medicinal as coping strategies } \\
\text { - Low organizational support was associated with high level STS }\end{array}$ \\
\hline
\end{tabular}

Age and years of experience of nursing are also not been connected and compare causing confusion about the real connection between age and STS, and how nursing in ED may contributes to STS rather than experience in emergency nursing. 
Similar to age, reports on relationship between gender and STS are contradicting. While, Măirean et al. found no relationship between gender and STS symptoms among emergency healthcare providers [34], Dominguez and Rutledge found that female nurses were more vulnerable to STS than male nurses [31]. In contrast, Petleski found that male nurses reported higher levels of STS symptoms than female nurses [35]. Differences in report and variation in years where studies conducted might speculate using different criteria to investigate STS resulting in variation in reported findings. Variation among these findings implies that gender does not relate STS, but these findings must be interpreted cautiously for three reasons: majority of ED nurses are females [16], female nurses had higher level of stress than male nurses [36], and female nurses had higher level of compassion fatigue than male nurses [37]. These inconsistent findings caused Hensel et al. to suggest the need for more research and further investigation to elucidate this relationship and the role of gender in STS [22]. Therefore, studies needed to investigate role of gender on developing STS considering feminism and maleness in nursing.

Another personal factor identified in the literature to predict the STS is the professional experience. Several studies assessed the relationship between professional experience and STS. This factor has been addressed in the literature in term of number of years in nursing and number of years in emergency unit. We have also found controversial reports on this factor. Four studies reported no association between experience and STS [9] [31] [34] [35]. On the other hand, an inverse relationship between STS and level of experience has been reported in the literature. Von Rueden et al. investigated a sample of 262 trauma nurses and found that nurses with fewer years of experience demonstrated higher level of STS [8]. This finding clearly suggests that junior nurses have greater rates of STS, and as nurses gained experience, their vulnerability to develop STS is decreased. Thinking broadly, experience in nursing is similar to age and, therefore; results have to be interpreted cautiously.

Coping capacity has been also identified as predictor for STS among helping professionals. Theoretically, coping has been conceptualized as protective factor against STS [2]. Probably, coping strategies assumed by ED nurses can mitigate the psychological impact of their exposure to traumatic stress in their every-day practice. This notion was empirically supported by Buurman et al. and Adriaenssens, et al. who found that coping is a significant predictor of STS development among ED nurses [6] [15]. Given that more stress is associated with reduced physical and mental health [38], Buurman et al. demonstrated that coping capacity explained one third of STS among nurses [6]. Studies found that nurses used drugs and alcohol as coping mechanism in response to the STS [1]. Von Rueden et al. have also found that ED nurses used medication to cope in response to STS [8]. It is believed that using more negative coping strategies would have worsened outcomes on ED nurses and deteriorates their status. There is a need to investigate nurses' perception of effective coping strategies to manage 
symptoms of STS, and what positive coping skills nurse can use to manage daily stressful situations.

Empathy is an important mechanism to develop STS symptoms among caring professionals [3]. However, Empathy was investigated in the literature and few studies found connection between empathy and STS. A study by MacRitchie, and Leibowitz investigated the relationship between level of shared empathy and STS among 64 trauma workers, and reported that empathy is a significant moderator between exposure to traumatic events and STS development [39]. This connection was sustained by Sheen et al. who reported that empathy was identified as a risk factor for STS in both quantitative and qualitative literature [40]. However, Crumpei and Dafinoiu investigated 77 medical workers from emergency and intensive care units including nurses and found no relationship between STS and empathy [41]. Despite the facts that empathy in nurses is viewed to enhance the positive outcomes of provided care [42], this relationship needs further scrutiny because of its negative effect on the ED nurses. Being involved in high empathetic relationship with traumatized patients may transfer trauma feelings from the patient to nurses and consequently place them at risk for developing STS.

Another assumed to play a role in development of STS is the amount of perceived social support. Social support is a broad, complex, and may have various forms [43]. Relationship between perceived social support and STS has been established in several studies. Studies demonstrated that nurses and trauma workers who received high levels of social support found to have less STS symptoms [22]. The qualitative literature also identified that ED nurses viewed social support as preventive and beneficial tool for the management of STS [16]. It can be said that there is a consensus in the literature to recognize social support as a protective factor against developing of STS among ED nurses. Social support reduces the effect of work stress on the nurses who are exposed to stressful situations such as helping patients who scrimmage with death. Thus, reduce the occurrence of STS symptoms [44]. However, it may be more helpful to determine which social supportive behaviors and which sources of support would help ED nurses more to protect them from STS.

\subsubsection{Organizational Factors}

The characteristics of an organization may play a role in prevention or occurrence of STS among its professionals [45]. Work related conditions have been found to associate STS among healthcare professionals [40]. Dworkin et al. stated that organizational characteristics are more important than personal characteristics in developing STS [30]. Several studies examined the role of some organizational characteristics in developing STS. However, some of organizational characteristics and their relation to STS have been addressed by the literature such as organizational support and amount of trauma work load placed on the staff. The literature lacks information on other organizational characteristics such as clinical supervision, organizational culture, and organizational 
resources. Future research on the organizational predictors of STS has to consider controlling the demographic factors to clarify this relation.

Organizational support refers to "the extent to which an organization values its staff and their contributions and cares about their well-being" [[46], p. 2]. The empirical literature has emphasized the role of organizational support in development of STS among nurses. The existing literature demonstrated that organizational support is a significant predictor for STS symptoms, and ED nurses who received higher level of social support from their managers demonstrated lower levels of STS symptoms [1] [8] [9] [22]. Work load is also one of the organizational characteristics suggested to contribute to STS among ED nurses [45]. Theoretically, Mealer and Jones described exposure to traumatic events through direct patient care as the main antecedent to develop STS among nurses [2]. This notion was empirically supported by several studies. High trauma case load has been found to relate development of STS symptoms among ED nurses [15] [47]. The qualitative literature also concluded similar findings. Morrison and Joy reported that junior nurses viewed exposing to traumatic events in workplace as a contributing factor for development of STS [16]. Studies from other disciplines also reported similar findings. It has been found that higher case loads accounted for unique variance of STS among providers working with survivors of sexual assault [30]. The literature has identified different empirical indicators for trauma case load such as; severity of trauma cases, length of contact with the traumatized victim, number of traumatized victims in nurse's load, and frequency of exposure to traumatized patients. Although the association between STS and exposure to traumatic events has been well established, further research is required to identify which aspects of this exposure play significant role in development of STS. Another aspect of organizational characteristics is the clinical supervision obtained from managers and supervisors. Little information is available on this factor. Dworkin et al. examined the relationship between supervision and STS and found that supervision accounted for unique variance in staff STS [30]. Based on this, nurses who receive higher levels of clinical supervision from their managers tend to develop less STS symptoms. Clinical supervision is emerging concept in nursing. The literature lacks information about how clinical supervision can be used to prevent the occurrence of STS among nurses and alleviate its consequences.

\section{Discussion}

The literature that has been reviewed for this study highlights the extent of the work that has been undertaken in this field. Much of the work has emphasized prevalence and factors associated with STS, however; studies were controversial in terms of rates and factors predicting STS among nurses in emergency units. There were also efforts that attempted to explain occurrence of STS and consequences of STS on nurses and quality of care. Nevertheless, little work concerned with sociodemographic and organizational factors that may predict or result into 
severe consequences of STS. Furthermore, studies were also emphasizing secondary trauma among caregivers neglecting that health care professionals including nurses in ED are vulnerable to STS, as well. The literature is raising a question that need to be answered; what are the factors that enhance or attenuate occurrence of STS among ED nurse? The current review is, to our knowledge, the first integrative review aimed to examine the factors attribute to or attenuate occurrence of STS among the nurses in emergency department. The predominant theme of the reviewed literature on STS predictors suggests that factors associated with STS development are categorized into personal and organizational factors. The identified factors can be either risk or preventive factors. The vast majority of the studies examined STS factors were conducted in last 20 years inferring recent aware about serious consequences of STS on nurses. It was noted that initial studies focused on the personal factors, while recent ones focused on and organizational ones. Research track in this perspective did not show those researchers were seriously emphasizing STS as one serious issue that influence nurses in ED. However, these studies were mainly screening for STS rather than establishing a scientific merit or theoretical explanation for STS among nurses.

Pertinent studies showed that prevalence of STS symptoms among ED nurses vary [15]. The high prevalence of STS infers that ED nurses are suffering serious consequences of STS [31]. The figures provided in literature infer that ED nurses have higher levels of STS in comparison to other nurses. This sustains the notion that being exposed to traumatized and lifesaving health care problems are increasing the risk to STS. Nursesdue to over exposure to traumas and life threatening situations are acting like being directly threaten. Crumpei and Dafinoiu have supported this theme and concluded that nurses in ED who are interacting directly with traumatized patients experience higher level of traumatic stress in comparison to other professionals [41]. However, and as mentioned, studies were not consistent in reporting the prevalence rates of STS symptoms among nurses. Lack of conceptual clarity about the concept of STS among the researchers could be one of possible causes for inconsistency [18]. This suggests a need to establish a solid measurement issue and methodology to examine STS and longitudinal cohort studies to form a clear perspective about STS incidence and prevalence among nurse in ED. Additionally, the designs used to explore the STS factors among ED nurses seem to be inadequate to capture the whole aspects of this phenomenon. All of the studies included in the current review used nonexperimental designs lacking causality between the identified factors and STS. Moreover, most of the studies investigated STS among EDnurses worldwide are primarily subscribed to quantitative methodology, while few ones investigated STS among nurses utilizing qualitative approach. There is a significant knowledge gap in how EDnurses experience the traumatic events in their daily practice in light of its personal, organizational, and social context. This gap was probably created due to lack of emphasis on the context of traumatic stress experience. 
The current review raised a concern about the factors investigated in the pertinent studies and thought to be related to STS. Studies have repetitively measured almost same list of variables conceptualized as predictors for STS symptoms. However, rational behind selecting these variables was not clear and never been linked to theoretical framework. Therefore, it is thought that these studies failed to capture all predictors of STS and a number of personal and organizational factors that are probably predicting STS have been ignored.

On the other hand, STS theories addressed the role of the personal factors in the development of STS. However, the empirical literature did not find this notion as true for all proposed personal factors. We have also found that reports regarding age, gender, education, and professional experience are contradicting. Other personal factors; coping capacity, empathy, and social support were empirically supported as predictors of STS among ED nurses. This review is supporting previous reports that personal factors have very little influence on STS [30], some, but not all personal factors were associated with STS [22]. This review also support the conclusion reached by Morrison and Joy that nurses in ED had a perception that personal characteristics are not related to STS symptoms [16]. In conclusion, demographic factors are not definitely related to STS development among nurses, while other personal factors may have buffering role in this process. More work is needed to examine the role of personal factors in STS to better understand for the process by which STS is developed. Researchers have to build a rational for including the personal factors in the future studies.

Overall, the current review proposes that there are group of personal and organizational factors that attenuate or enhance occurrence of STS among ED nurses. However, it was not easy to make comparisons between the findings and draw conclusions for many reasons due to contradicting findings and inconsistent conceptual background of STS in studies. Lack of similarity across the studies in terms of scales used and reported outcomes were obstacles to reach a conclusion on the identified factors. The psychological and social factors such as social support and empathy were extensively investigated ignoring other factors such as traumatic experience, type of trauma and coping efficacy. There are few potential sources of bias have to be considered prior to draw conclusion from the findings of the current review. We used broad subject headings and key words combinations for search. However, this may have resulted in omission of relevant articles. Additionally, we may have not identified articles that were not indexed in the targeted databases. Also this review included only studies published in English. Perhaps relevant literature published in other languages has been omitted.

\section{Conclusion}

Nurses in ED are at high risk for STS and are under investigated in terms of predictors and consequences compared to other vulnerable groups such caregivers. It is obvious that nurses working in ED are likely affected by exposure to trau- 
matic events in encountered in their practice. Exposure to traumatic events could adversely affect ED nurses' well-being, organizational outcomes, and quality of care provided. Nurses need to be aware about factors contribute to STS, and training for such groups is a priority at this field. The literature tested empirically some factors, whereas some factors still require further investigations. Longitudinal and qualitative approach need to be adopted to better understand the phenomenon. In addition, quality care manager and policy maker should observe consequences of STS in ED nurse as part of their quality improvement protocols.

\section{References}

[1] Duffy, E., Avalos, G. and Dowling, M. (2015) Secondary Traumatic Stress among Emergency Nurses: A Cross-Sectional Study. International Emergency Nursing, 23, 53-58. https://doi.org/10.1016/j.ienj.2014.05.001

[2] Mealer, M. and Jones, J. (2013) Posttraumatic Stress Disorder in the Nursing Population: A Concept Analysis. Nursing Forum, 48, 279-288.

[3] Stamm, B.H. (2010) The Concise ProQOL Manual. 2nd Edition, Pocatello, ID: ProQOL.org.

[4] Kessler, R.C., McLaughlin, K.A., Koenen, K.C., Petukhova, M. and Hill, E.D. (2012) The Importance of Secondary Trauma Exposure for Post-Disaster Mental Disorder. Epidemiology and Psychiatric Sciences, 21, 35-45. https://doi.org/10.1017/S2045796011000758

[5] American Psychiatric Association (2013) Diagnostic and Statistical Manual of Mental Disorders. 5th Edition, Author, Washington DC.

https://doi.org/10.1176/appi.books.9780890425596

[6] Buurman, B.M., Mank, A.P., Beijer, H.J. and Olff, M. (2011) Coping with Serious Events at Work A Study of Traumatic Stress among Nurses. Journal of the American Psychiatric Nurses Association, 17, 321-329. https://doi.org/10.1177/1078390311418651

[7] McGibbon, E., Peter, E. and Gallop, R. (2010) An Institutional Ethnography of Nurses' Stress. Qualitative Health Research. https://doi.org/10.1177/1049732310375435

[8] Von Rueden, K.T., Hinderer, K.A., McQuillan, K.A., Murray, M., Logan, T., Kramer, B., et al. (2010) Secondary Traumatic Stress in Trauma Nurses: Prevalence and Exposure, Coping, and Personal/Environmental Characteristics. Journal of Trauma Nursing, 17, 191-200. https://doi.org/10.1097/JTN.0b013e3181ff2607

[9] Hunsaker, S., Chen, H.C., Maughan, D. and Heaston, S. (2015) Factors That Influence the Development of Compassion Fatigue, Burnout, and Compassion Satisfaction in Emergency Department Nurses. Journal of Nursing Scholarship, 47, 186-194. https://doi.org/10.1111/jnu.12122

[10] Whittemore, R. and Knafl, K. (2005) The Integrative Review: Updated Methodology. Journal of Advanced Nursing, 52, 546-553. https://doi.org/10.1111/j.1365-2648.2005.03621.x

[11] Critical Appraisal Skills Programme (CASP) (2017) Appraising the Evidence Checklist. CASP, Oxford. http://www.casp-uk.net/\#!untitled/cd2g

[12] Figley, C.R. (1995) Epilogue: The Transmission of Trauma. In: Figley, C.R., Ed., Compassion Fatigue: Coping with Secondary Traumatic Stress Disorder in Those 
Who Treat the Traumatized, Brunner/Mazel, New York, 249-254.

[13] Dutton, M.A. and Rubinstein, F.L. (1995) Working with People with PTSD: Research Implications. In: Figley, C.R., Ed., Compassion Fatigue: Coping with Secondary Traumatic Stress Disorder in Those Who Treat the Traumatized, Brunner/Mazel, New York, 82-100.

[14] Conti-O'Hare, M. (2002) The Nurse as Wounded Healer: From Trauma to Transcendence. Jones \& Bartlett Learning, Burlington.

[15] Adriaenssens, J., De Gucht, V. and Maes, S. (2012) The Impact of Traumatic Events on Emergency Room Nurses: Findings from a Questionnaire Survey. International Journal of Nursing Studies, 49, 1411-1422. https://doi.org/10.1016/j.ijnurstu.2012.07.003

[16] Morrison, L.E. and Joy, J.P. (2016) Secondary Traumatic Stress in the Emergency Department. Journal of Advanced Nursing, 72, 2894-2906. https://doi.org/10.1111/jan.13030

[17] Bride, B.E. (2007) Prevalence of Secondary Traumatic Stress among Social Workers. Social Work, 52, 63-70. https://doi.org/10.1093/sw/52.1.63

[18] Beck, C.T. (2011) Secondary Traumatic Stress in Nurses: A Systematic Review. Archives of Psychiatric Nursing, 25, 1-10. https://doi.org/10.1016/j.apnu.2010.05.005

[19] Watts, J. and Robertson, N. (2015) Selecting a Measure for Assessing Secondary Trauma in Nurses. Nurse Researcher, 23, 30-35. https://doi.org/10.7748/nr.23.2.30.s7

[20] Mealer, M.L., Shelton, A., Berg, B., Rothbaum, B. and Moss, M. (2007) Increased Prevalence of Post-Traumatic Stress Disorder Symptoms in Critical Care Nurses. American Journal of Respiratory and Critical Care Medicine, 175, 693-697. https://doi.org/10.1164/rccm.200606-735OC

[21] Beck, C.T. and Gable, R.K. (2012) A Mixed Methods Study of Secondary Traumatic Stress in Labor and Delivery Nurses. Journal of Obstetric, Gynecologic, \& Neonatal Nursing, 41, 747-760. https://doi.org/10.1111/j.1552-6909.2012.01386.x

[22] Hensel, J.M., Ruiz, C., Finney, C. and Dewa, C.S. (2015) Meta-Analysis of Risk Factors for Secondary Traumatic Stress in Therapeutic Work with Trauma Victims. Journal of Traumatic Stress, 28, 83-91. https://doi.org/10.1002/jts.21998

[23] Cardozo, B.L., Crawford, C.G., Eriksson, C., Zhu, J., Sabin, M., Ager, A. and Olff, M. (2012) Psychological Distress, Depression, Anxiety, and Burnout among International Humanitarian Aid Workers: A Longitudinal Study. PloS One, 7, e44948.

[24] Kirchhof, R.S., Guido, L.D.A., Freitas, E.D.O., Benetti, E.R.R. and Lopes, L.F.D. (2012) Stress among Emergency Nurses. Journal of Nursing UFPE on Line, 6 , 2927-2933.

[25] Rainville, C. (2015) Understanding Secondary Trauma: A Guide for Lawyers Working with Child Victims. ABA Child Law Practice, 34. https://www.americanbar.org

[26] Donnelly, E. and Siebert, D. (2009) Occupational Risk Factors in the Emergency Medical Services. Prehospital and Disaster Medicine, 24, 422-429. https://doi.org/10.1017/S1049023X00007251

[27] Bride, B.E. and Kintzle, S. (2011) Secondary Traumatic Stress, Job Satisfaction, and Occupational Commitment in Substance Abuse Counselors. Traumatology, 17, 22-28. https://doi.org/10.1177/1534765610395617

[28] Cieslak, R., Shoji, K., Douglas, A., Melville, E., Luszczynska, A. and Benight, C.C. (2014) A Meta-Analysis of the Relationship between Job Burnout and Secondary 
Traumatic Stress among Workers with Indirect Exposure to Trauma. Psychological Services, 11, 75-86. https://doi.org/10.1037/a0033798

[29] Gavrilovici, C., Gavrilescu, S. and Miron, L. (2013) Pleading for the Quality of Health Care: Ethics-From the Bedside to Health Institutions. Revista Romana de Bioetica, 11, 3-5.

[30] Dworkin, E.R., Sorell, N.R. and Allen, N.E. (2016) Individual- and Setting-Level Correlates of Secondary Traumatic Stress in Rape Crisis Center Staff. Journal of Interpersonal Violence, 31, 743-752. https://doi.org/10.1177/0886260514556111

[31] Dominguez-Gomez, E. and Rutledge, D.N. (2009) Prevalence of Secondary Traumatic Stress among Emergency Nurses. Journal of Emergency Nursing, 35, 199-204. https://doi.org/10.1016/j.jen.2008.05.003

[32] Najjar, N., Davis, L., Beck-Coon, K. and Doebbeling, C. (2009) Compassion Fatigue: A Review of the Research to Date and Relevance to Cancer-Care Providers. Journal of Health and Psychology, 14, 267-277. https://doi.org/10.1177/1359105308100211

[33] Townsend, S.M. and Campbell, R. (2009) Organizational Correlates of Secondary Traumatic Stress and Burnout among Sexual Assault Nurse Examiners. Journal of Forensic Nursing, 5, 97-106. https://doi.org/10.1111/j.1939-3938.2009.01040.x

[34] Mairean, C., Cimpoesu, D. and Turliuc, M.N. (2014) The Effects of Traumatic Situations on Emergency Medicine Practitioners. Revista de cercetare si interventie sociala, 44, 279-290.

[35] Petleski, T.A. (2013) Compassion Fatigue among Emergency Department Nurses. Gardner-Webb University, Boiling Springs.

[36] Komachi, M.H., Kamibeppu, K., Nishi, D. and Matsuoka, Y. (2012) Secondary Traumatic Stress and Associated Factors among Japanese Nurses Working in Hospitals. International Journal of Nursing Practice, 18, 155-163. https://doi.org/10.1111/j.1440-172X.2012.02014.x

[37] Sacco, T.L., Ciurzynski, S.M., Harvey, M.E. and Ingersoll, G.L. (2015) Compassion Satisfaction and Compassion Fatigue among Critical Care Nurses. Critical Care Nurse, 35, 32-42. https://doi.org/10.4037/ccn2015392

[38] Fink, G. (2011) Stress Controversies: Post-Traumatic Stress Disorder, Hippocampal Volume, Gastroduodenal Ulceration. Journal of Neuroendocrinology, 23, 107-117. https://doi.org/10.1111/j.1365-2826.2010.02089.x

[39] MacRitchie, V. and Leibowitz, S. (2010) Secondary Traumatic Stress, Level of Exposure, Empathy and Social Support in Trauma Workers. South African Journal of Psychology, 40, 149-158. https://doi.org/10.1177/008124631004000204

[40] Sheen, K., Slade, P. and Spiby, H. (2014) An Integrative Review of the Impact of Indirect Trauma Exposure in Health Professionals and Potential Issues of Salience for Midwives. Journal of Advanced Nursing, 70, 729-743. https://doi.org/10.1111/jan.12274

[41] Crumpei, I. and Dafinoiu, I. (2012) The Relation of Clinical Empathy to Secondary Traumatic Stress. Procedia-Social and Behavioral Sciences, 33, 438-442. https://doi.org/10.1016/j.sbspro.2012.01.159

[42] Pohl, S., Saiani, L. and Battistelli, A. (2013) Empathy in the Emotional Interactions with Patients. Is It Positive for Nurses Too? Journal of Nursing Education and Practice, 4, 74-81.

[43] Hamdan-Mansour, A. (2016) Social Support and Adolescents' Alcohol Use: An Integrative Literature Review. Health, 8, 1166-1177. https://doi.org/10.4236/health.2016.812120 
[44] Ariapooran, S. (2014) Compassion Fatigue and Burnout in Iranian Nurses: The Role of Perceived Social Support. Iranian Journal of Nursing and Midwifery Research, 19, 279-284.

[45] Choi, G.Y. (2010) The Influence of Organizational Characteristics and Psychological Empowerment on Secondary Traumatic Stress of Social Workers Working with Family Violence or Sexual Assault Survivors. $22^{\text {nd }}$ National Symposium on Doctoral Research in Social Work, Ohio State University, College of Social Work.

[46] Kurtessis, J.N., Eisenberger, R., Ford, M.T., Buffardi, L.C., Stewart, K.A. and Adis, C.S. (2015) Perceived Organizational Support a Meta-Analytic Evaluation of Organizational Support Theory. Journal of Management, 31, 874-900.

[47] de Boer, J.C., Lok, A., van't Verlaat, E., Duivenvoorden, H.J., Bakker, A.B. and Smit, B.J. (2011) Work-Related Critical Incidents in Hospital-Based Health Care Providers and the Risk of Post-Traumatic Stress Symptoms, Anxiety, and Depression: A Meta-Analysis. Social Science \& Medicine, 73, 316-326.

https://doi.org/10.1016/j.socscimed.2011.05.009 